\title{
Effect of Zinc Nitrate Concentration on the Morphology and Optical Properties of ZnO Nanorod Arrays
}

\author{
Jiangni Yun ${ }^{1,} \mathrm{a}^{*}$, Yanni Zhang ${ }^{1}$, Keyun Wang ,Jun $\mathrm{Li}^{1}$, and Zhiyong Zhang ${ }^{1, \mathrm{~b}}$ \\ ${ }^{1}$ School of Information Science and Technology, Northwest University, Xi'an, 710127, China \\ aniniyun@nwu.edu.cn, bhangzy@nwu.edu.cn
}

\begin{abstract}
Keywords: $\mathrm{ZnO}$ nanorod arrays, morphology and optical properties, hydrothermal method
\end{abstract} Abstract. In this paper, the effect of the zinc nitrate concentration on the morphology and optical properties of $\mathrm{ZnO}$ nanorod arrays synthesized by hydrothermal method was investigated. The microstructure, morphology and optical properties of the as-prepared samples were characterized by x-ray diffraction (XRD), scanning electron microscope (SEM) and photoluminescence spectrum (PL). The results show that the $\mathrm{ZnO}$ nanorods had wurzite structures with cell parameters of $\mathrm{a}=3.249 \AA$ and $\mathrm{c}=5.026 \AA$. The morphology and average diameter of $\mathrm{ZnO}$ nanorod arrays were found to be dependent on the $\mathrm{Zn}\left(\mathrm{NO}_{3}\right)_{2}$ concentrations. The diameter of $\mathrm{ZnO}$ nanorod arrays increase with the increase in the mole density of the $\mathrm{Zn}\left(\mathrm{NO}_{3}\right)_{2}$. The value and position of PL spectra also were varied by changing the concentration of the $\mathrm{Zn}\left(\mathrm{NO}_{3}\right)_{2}$ precursor.

\section{Introduction}

$\mathrm{ZnO}$ semiconductor materials with its wide band gap $(\mathrm{Eg}=3.37 \mathrm{eV})$ and high exciton binding energy $(60 \mathrm{meV})$ has been one of the most promising oxide semiconducting materials. Since the first report of ultraviolet lasing from $\mathrm{ZnO}$ nanowires[1], one-dimensional (1D) semiconductor materials have widely attracted much interest for constructing future nanoscale electronic and optoelectronic devices. Over the past few years, 1D ZnO nanostructures have been synthesized with various methods including vapor-liquid-solid (VLS) growth[1], MOCVD[2], electrochemical deposition[3],template-based synthesis[4] and hydrothermal method[5]. ZnO nanorod arrays, as an ordered nanometer structure, have become a new and hot research topic, which converged the unique properties of collective effect, synergy effect and coupling effect. Though $\mathrm{ZnO}$ nanorod arrays have been synthesized by Yang's group [6], the research regarding the effect on the optical, electrical and magnetic properties of technological parameter is not enough. Furthermore, systematic studies on the effect of the zinc nitrate concentration on the morphology and the optical properties of $\mathrm{ZnO}$ nanorod arrays grown on the substrate by the hydrothermal method are meaningful for future electronic and optoelectronic devices application.

This paper reports the effect of the zinc nitrate concentration on the morphology and the optical properties of $\mathrm{ZnO}$ nanorod arrays grown on the substrate by using the hydrothermal method. X-ray diffraction ((SHIMADZU LIMITED, XRD-7000)) and Scanning electron microscopy (JEOL, JSM-6390A) measurements were performed to characterize the structural properties of formed $\mathrm{ZnO}$ nanostructures. The elemental composition was characterized by energy dispersive X-ray spectroscopy (attached to the SEM). Photoluminescence (HORIBA, FluoroMax-4p) measurements with a Xenon lamp as the excitation source at room temperature were performed to investigate the optical properties of the $\mathrm{ZnO}$ nanostructures.

\section{Experimental procedure}

The procedure of the $\mathrm{ZnO}$ nanorod arrays prepared under hydrothermal condition consists of two steps. (1) A layer of $\mathrm{ZnO}$ seed crystal was deposited on the $\mathrm{Si}(100)$ wafer $\left(1.2 \mathrm{~cm}^{*} 1.2 \mathrm{~cm}\right)$ via sol-gel method. In detail, equal molar $\mathrm{Zn}\left(\mathrm{CH}_{3} \mathrm{COO}\right)_{2}-2 \mathrm{H}_{2} \mathrm{O}(0.35 \mathrm{~mol} / \mathrm{L})$ and ethanolamine were solved in 2-methoxyethanol with stirring at $60^{\circ} \mathrm{Cfor} 4 \mathrm{~h}$ to yield a homogeneous solution. Subsequently, the precursor solution was dropped on the Si wafer, spunning at 300r/min for $5 \mathrm{~s}$ and then $3000 \mathrm{r} / \mathrm{min}$ for 
$10 \mathrm{~s}$. Then the substrate was heated to $700^{\circ} \mathrm{C}$ for $2 \mathrm{~h}$ to obtain a dense and transparent $\mathrm{ZnO}$ seed layer on the Si substrate. (2)The precursor solutions were prepared by mixing equimolar $\mathrm{Zn}\left(\mathrm{NO}_{3}\right)_{2}$ and $\left(\mathrm{CH}_{2}\right)_{6} \mathrm{~N}_{4}$. The concentration of $\mathrm{Zn}^{2+}$ contains (a) $0.0025 \mathrm{~mol} / \mathrm{L}$ (b) $0.05 \mathrm{~mol} / \mathrm{L}$ (c) $0.1 \mathrm{~mol} / \mathrm{L}$ (d) $0.2 \mathrm{~mol} / \mathrm{L}$. The Si wafer with a layer of $\mathrm{ZnO}$ seed crystal is up-right in the autoclave, and hydrothermal growth was carried out at $90^{\circ} \mathrm{C}$ for 5 hours. After the reaction, the Si wafer was removed from the solution rinsed with deionized water and then dried at room temperature.

\section{Results and discussion}

Fig. 1 shows XRD patterns of samples grown with different $\mathrm{Zn}\left(\mathrm{NO}_{3}\right)_{2}$ concentration (a) $0.0025 \mathrm{~mol} / \mathrm{L}$ (b) $0.05 \mathrm{~mol} / \mathrm{L}$ (c) $0.1 \mathrm{~mol} / \mathrm{L}$ (d) $0.2 \mathrm{~mol} / \mathrm{L}$. XRD patterns show the samples have wurzite structures with cell parameters of $\mathrm{a}=3.249 \AA$ and $\mathrm{c}=5.026 \AA$. No other peak oppears in the XRD data, indicating that only single-phase $\mathrm{ZnO}$ nanosturctures are formed. Nevertheless, compared with standard PDF card(JCPDS No.36-1451) of ZnO powders, the (002) and (103) diffraction peak of samples intensify, indicating that the $\mathrm{ZnO}$ crystallites have the trend of preferred orientation growth along (002) and (103) plane and are highly oriented with their c-axes being perpendicular to the Si substrates.

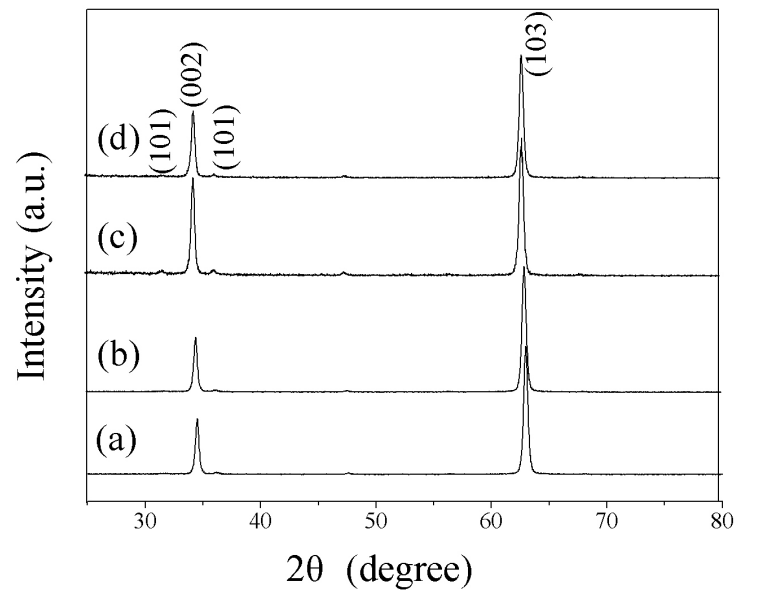

Fig. 1 XRD patterns of $\mathrm{ZnO}$ nanorod array with different $\mathrm{Zn}\left(\mathrm{NO}_{3}\right)_{2}$ concentration.

Fig. 2 (a)-(d) shows the SEM images of $\mathrm{ZnO}$ nanorod arrays grown with different $\mathrm{Zn}\left(\mathrm{NO}_{3}\right)_{2}$ concentrations. Fig.2(a-c) shows nanorod arrays consisted of a great amount of nanorods which grew independently, had six prism structure and separated among the upper apex one another. Fig.2(d), the nanorods have the six prism structure as well, but compared to (a-c), arranged closely, squeeze each other and the upper apex almost connect. The single crystal of $\mathrm{ZnO}$ nanorod arrays are formed by the combination of the growth units $\left[\mathrm{Zn}(\mathrm{OH})_{4}\right]^{2-}$ that are connected each other so as to achieve the state of surface energy minimization. Because of the alkaline solution and $\mathrm{ZnO}$ seed layer on the Si substrate, $\mathrm{ZnO}$ nanorods achieved homogeneous epitaxial growth. $\mathrm{ZnO}$ nanorod arrays can ultimately be formed when a large amount of $\mathrm{ZnO}$ nanorods grew simultaneously vertically on the substrate. The growth rate of various crystal faces is:

$$
(0001)>(10 \overline{1} 1)>(10 \overline{1} 0)>(000 \overline{1}) .
$$

The morphology and average diameter of $\mathrm{ZnO}$ nanorod arrays were found to be dependent on the $\mathrm{Zn}\left(\mathrm{NO}_{3}\right)_{2}$ concentrations. The average diameter is $74 \mathrm{~nm}, 111 \mathrm{~nm}, 224 \mathrm{~nm}, 535 \mathrm{~nm}$ respectively. The diameter of $\mathrm{ZnO}$ nanorod arrays increase due to an increase in the ratio between the $\mathrm{OH}^{-}$generation and the $\mathrm{Zn}^{2+}$ diffusion with an increase in the mole density of the $\mathrm{Zn}\left(\mathrm{NO}_{3}\right)_{2}$. The $\mathrm{ZnO}$ nanorods' average diameter became more larger caused by the crash probability of growth units became greater when the concentration of $\mathrm{Zn}\left(\mathrm{NO}_{3}\right)_{2}$ became greater. Fig. 4 shows the chemical composition of the $\mathrm{ZnO}$ nanorod arrays determined by EDS. Only oxygen and zinc signals could be detected, and the content of oxygen atom is larger than the zinc atom.

Fig. 3 shows the PL spectra of the $\mathrm{ZnO}$ nanorod arrays formed by using different $\mathrm{Zn}\left(\mathrm{NO}_{3}\right)_{2}$ concentration of (a) $0.0025 \mathrm{~mol} / \mathrm{L}$ (b) $0.05 \mathrm{~mol} / \mathrm{L}$ (c) $0.1 \mathrm{~mol} / \mathrm{L}$ (d) $0.2 \mathrm{~mol} / \mathrm{L}$. The spectrum of all samples consists of UV emission and green emission. 

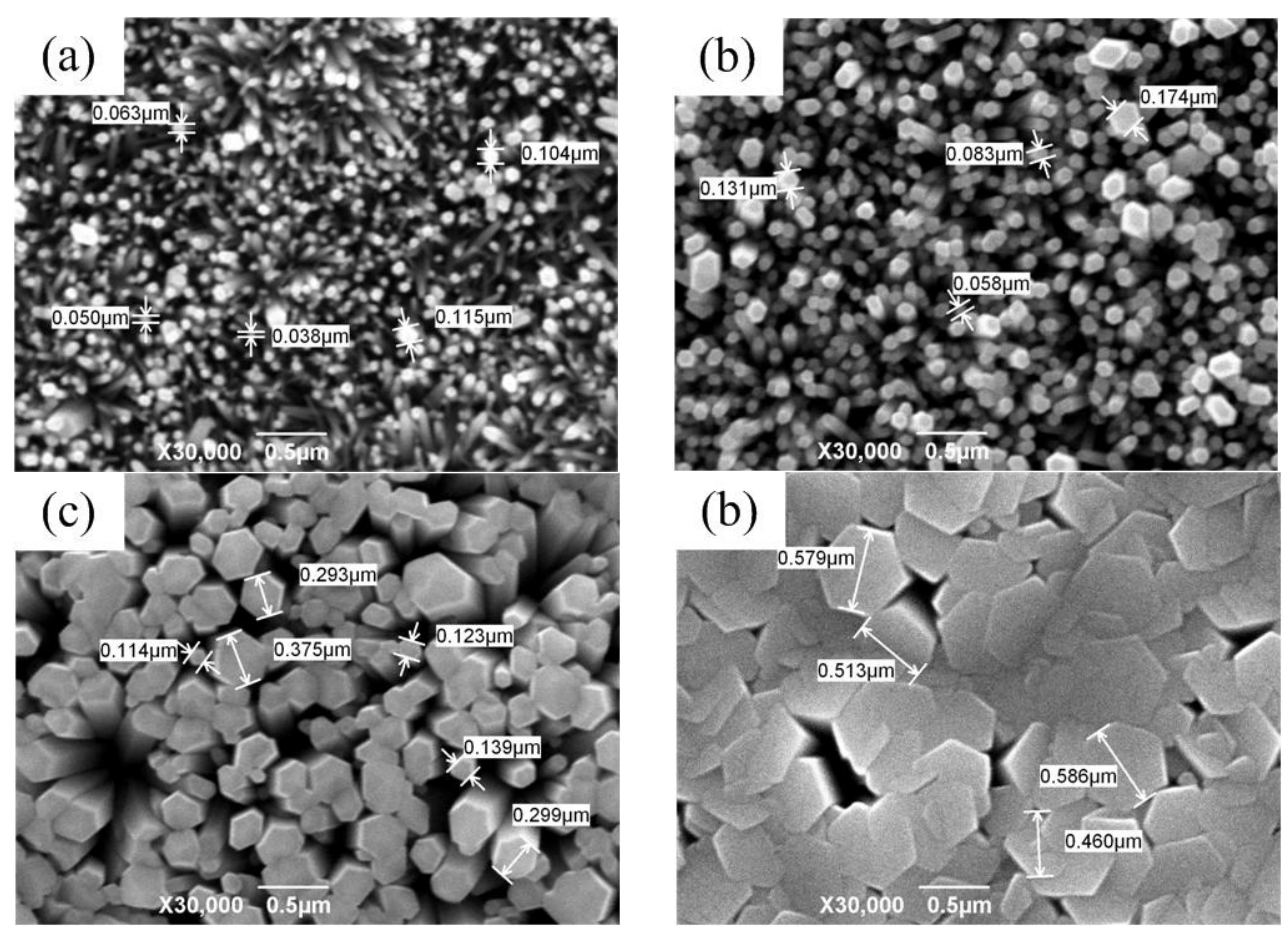

Fig.2 (a)-(d) The SEM images of $\mathrm{ZnO}$ nanorod arrays grown with different $\mathrm{Zn}\left(\mathrm{NO}_{3}\right)_{2}$ concentrations. (a) $0.0025 \mathrm{~mol} / \mathrm{L}$ (b) $0.05 \mathrm{~mol} / \mathrm{L}$ (c) $0.1 \mathrm{~mol} / \mathrm{L}$ (d) $0.2 \mathrm{~mol} / \mathrm{L}$.

Table 1 The EDS analysis of the $\mathrm{ZnO}$ nanorod arrays grown with different $\mathrm{Zn}\left(\mathrm{NO}_{3}\right)_{2}$ concentrations.

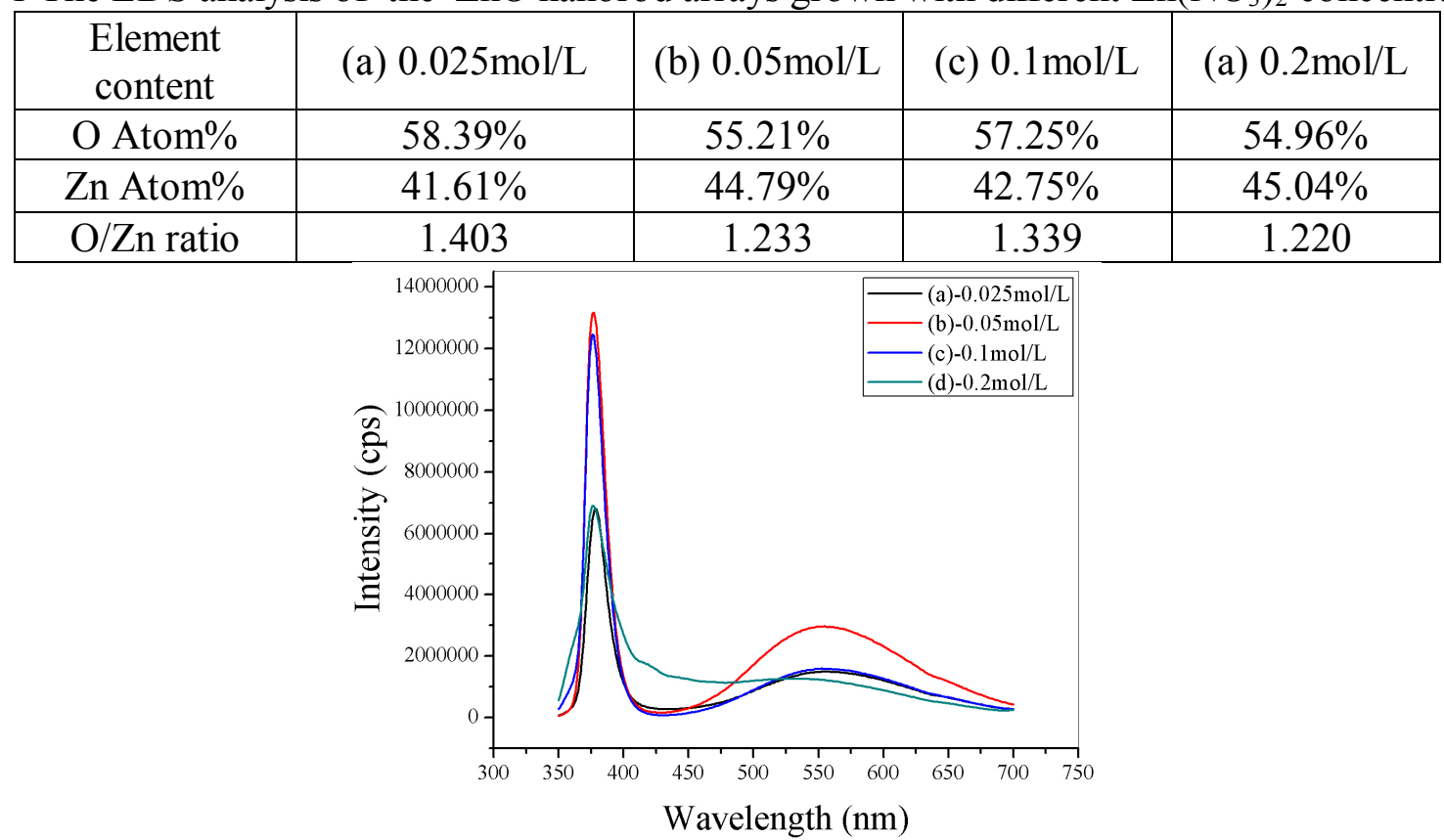

Fig. 3 The room temperature PL spectrum of $\mathrm{ZnO}$ nanorod arrays with different $\mathrm{Zn}\left(\mathrm{NO}_{3}\right)_{2}$ concentrations.

The crystalline quality of $\mathrm{ZnO}$ nanorods is very good because the ratio of two emissions reached $4.54,4.44,7.83$ and 5.58 respectively. The UV peak positions of samples are $378 \mathrm{~nm}, 377 \mathrm{~nm}, 376 \mathrm{~nm}$ and $376 \mathrm{~nm}$ respectively which is commonly attributed to the recombination of free excitons via exciton-exciton collision process. Blue shift of the UV peak positions can be obeserved with the increase of $\mathrm{Zn}\left(\mathrm{NO}_{3}\right)_{2}$ concentration. Considering the Bohr radius of $\mathrm{ZnO}$ is 2.34, the explanation of blue shift due to quantum confinement in $\mathrm{ZnO}$ nanorod arrays with diameters $74 \mathrm{~nm}, 111 \mathrm{~nm}, 224 \mathrm{~nm}$, $535 \mathrm{~nm}$ is controversial. If exciton quenching occurs due to the intrinsic defect, one possible reason for the blue shift is different concentration of intrinsic defects on the surface. The spectrum shape and position would be affected by defect density on the suface which varied due to different nanostructure 
size and different surface-to-volume ratios. The green band emission at 558nm, 554nm, 552nm and $548 \mathrm{~nm}$ can be observed respectively. There have been many hypotheses proposed include singly ionized oxygen vacancies [7], antisite oxygen[8], zinc vacancy[9], oxygen interstitial[8] to explain the emission from defect structure in the $\mathrm{ZnO}$ crystal. The EDS results shown in table 1 indicate defects might contain $\mathrm{O}$ interstitial, $\mathrm{Zn}$ vacancy or antisite oxygen. So, the green emission of zinc oxide might results from the electron transition from the conduction band to the antisite defect $\mathrm{O}_{\mathrm{Zn}}$ or $\mathrm{O}_{\mathrm{i}}$ level.Though green emission is related to the defects in the $\mathrm{ZnO}$, exact mechanism requires further study.

\section{Conclusions}

In conclusion, the effect of the zinc nitrate concentration on the morphology and optical properties of $\mathrm{ZnO}$ nanorod arrays on the Si substrates by using hydrothermal method was investigated. XRD patterns showed that the $\mathrm{ZnO}$ nanorods had wurzite structures with cell parameters of $\mathrm{a}=3.249 \AA$ and $\mathrm{c}=5.026 \AA$. The morphology and average diameter of $\mathrm{ZnO}$ nanorod arrays were found to be dependent on the $\mathrm{Zn}\left(\mathrm{NO}_{3}\right)_{2}$ concentrations. The diameter of $\mathrm{ZnO}$ nanorod arrays increase with the increase in the mole density of the $\mathrm{Zn}\left(\mathrm{NO}_{3}\right)_{2}$. The value and position of PL spectra also were varied by changing the concentration of the $\mathrm{Zn}\left(\mathrm{NO}_{3}\right)_{2}$ precursor.

\section{Acknowledgements}

This work is supported by National Natural Science Foundation of China (61306009) and the Science and Technology Star Project of Shaanxi Province (2013KJXX-24).

\section{References}

[1] M H.Huang, S.Mao, H.Feick, et al.: Science., Vol.292(2001), p.1897

[2] J.L.Yang, S.J.An, W.L.Park: Advanced Materials., Vol.18(2004), p.1661

[3] R.Liu, A.A Vertegel, E W.Bohannan, et al.: Chem Mater., Vol.13(2001),p.508

[4] C.Liu, J.A.Zapien, Y.Yao, et al.: Advanced Materials., Vol.15(2003), p.838

[5] M.Wang, C.H.Ye, Y.Zhang, et al.: Journal of Crystal Growth., Vol.291( 2006), p.334

[6] L.E.Greene, M.Law, P.D.Yang, et al.. Angewandte Chemie., Vol.42(2003), p.3031

[7] K.Vanheusden, W.L.Warren, C.H.Seager, et al.. Journal of Applied Physics., Vol.79(1996), p.7983

[8] B.X.Lin, Z.X.Fu, Y.B.Jia:Appl. Phys. Lett., Vol.79(2001), p. 942

[9] Q.X.Zhao, P.Klason, M.Willander, et al. :Appl. Phys. Lett., Vol.87(2005), p. 211912 